\title{
Subclinical Bovine Spongiform Encephalopathy Infection in Transgenic Mice Expressing Porcine Prion Protein
}

\author{
Joaquín Castilla, ${ }^{1}$ Alfonso Gutiérrez-Adán, ${ }^{2}$ Alejandro Brun, ${ }^{1}$ Deirdre Doyle,${ }^{3}$ Belén Pintado, ${ }^{2}$ Miguel A. Ramírez, ${ }^{2}$ \\ Francisco J. Salguero, ${ }^{1}$ Beatriz Parra, ${ }^{1}$ Fayna Díaz San Segundo, ${ }^{1}$ José M. Sánchez-Vizcaíno, ${ }^{1}$ Mark Rogers,${ }^{3}$ and \\ Juan M. Torres ${ }^{1}$ \\ ${ }^{1}$ Centro de Investigación en Sanidad Animal, Instituto Nacional de Investigación y Tecnología Agraria y Alimentaria, Valdeolmos, 28130 Madrid, Spain, \\ ${ }^{2}$ Departamento de Reproducción Animal y Conservación de Recursos Zoogenéticos, 28040 Madrid, Spain, and 3 Department of Zoology and Conway \\ Institute for Biomolecular and Biomedical Research, University College Dublin, Belfield, Dublin 4, Ireland
}

The bovine-porcine species barrier to bovine spongiform encephalopathy (BSE) infection was explored by generating transgenic mouse lines expressing the porcine prion protein (PrP) gene. All of the porcine transgenic (poTg) mice showed clinical signs of BSE after intracerebral inoculation with a high-titer BSE inoculum. The protease-resistant $\operatorname{PrP}\left(\operatorname{PrP}^{\mathrm{res}}\right)$ was detected in $14 \%(3$ of 22$)$ of the BSE-infected poTg mice by immunohistochemical or immunoblot analysis. Despite being able to infect $42 \%$ ( 5 of 12 ) of control mice, a low-dose BSE inoculum failed to penetrate the species barrier in our poTg mouse model. The findings of these infectivity studies suggest that there is a strong species barrier between cows and pigs. However, after second-passage infection of poTg mice using brain homogenates of BSE-inoculated mice scoring negative for the incoming prion protein as inoculum, it was possible to detect the presence of the infectious agent. Thus, porcine-adapted BSE inocula were efficient at infecting poTg mice, giving rise to an incubation period substantially reduced from 300 to $177 \mathrm{~d}$ after inoculation and to the presence of $\mathrm{PrP}^{\text {res }}$ in $100 \%$ (21 of 21$)$ of the mice. We were therefore able to conclude that initial exposure to the bovine prion may lead to subclinical infection such that brain homogenates from poTg mice classified as uninfected on the basis of the absence of $\mathrm{PrP}^{\mathrm{res}}$ are infectious when used to reinoculate poTg mice. Collectively, our findings suggest that these poTg mice could be used as a sensitive bioassay model for prion detection in pigs.

Key words: BSE transmission; porcine prion; PrP; scrapie; transgenic mice; species barrier

\section{Introduction}

Prion diseases, or transmissible spongiform encephalopathies (TSEs), are neurodegenerative disorders that affect humans and animals, and are usually characterized by the presence of protease-resistant prion protein $\left(\mathrm{PrP}^{\mathrm{res}}\right)$, an abnormal, proteaseresistant isoform of the normal cell protein denoted $\operatorname{PrP}^{\mathrm{C}}$ (Prusiner, 1991). Sheep scrapie, the best recognized TSE disease in animals, has been identified in sheep for over 200 years (Pattison and Jones, 1967), but since the 1960s, TSEs have also been identified in mink (Hartsough and Burger, 1965) and mule deer (Williams and Young, 1980). The most recent and extensive outbreak of an animal TSE disease was bovine spongiform encephalopathy (BSE) in cattle occurring in the United Kingdom in the 1980s. BSE has important implications for human health, and the consumption of BSE-contaminated meat or meat products has been linked to the advent of a new human TSE disease, variant

Received Dec. 7, 2003; revised April 7, 2004; accepted April 9, 2004.

This work was supported by European Union Grant FAIR97-CT3306 and National Spanish Grant EET2002-05140. We thankJ.C. Manson for supplying the Prnp ${ }^{-1-}$ mice, D. R. Borchelt for supplying the MoPrP.Xho plasmid, and the Veterinary Laboratory Agency (Weybridge, UK) for supplying BSE brain material. We also thank Fernando Rodríguez for his critical reading of this manuscript.

Correspondence should be addressed to Dr. Juan María Torres Trillo, Centro de Investigación en Sanidad Animal, Instituto Nacional de Investigación y Tecnología Agraria y Alimentaria, Valdeolmos, 28130 Madrid, Spain. E-mail: jmtorres@inia.es.

DOI:10.1523/JNEUROSCI.5400-03.2004

Copyright $\odot 2004$ Society for Neuroscience $\quad$ 0270-6474/04/245063-07\$15.00/0
Creutzfeldt-Jakob disease (Collinge and Rossor, 1996; Collinge et al., 1996; Will and Zeidler, 1996; Scott et al., 1999). The potential spread of BSE to other domestic animals such as sheep and pigs has implications for human health, and these populations of animals need to be monitored for signs of BSE infection.

It is well recognized that the transmission of a TSE disease within the same species occurs efficiently, but between certain pairs of species, there is a strong barrier to transmission (Pattison and Jones, 1968; Prusiner, 1990; Kocisko et al., 1995). This barrier has been defined in terms of the amino acid identity of the incoming $\operatorname{PrP}^{\text {res }}$ and the resident $\operatorname{PrP}^{\mathrm{C}} ; 100 \%$ identity usually indicates the lack of a species barrier (Prusiner, 1990). However, recent data suggest that conformational differences, independent of the amino acid sequence, can also be a key determining factor in the species barrier (Peretz et al., 2001).

Understanding the species barrier is crucial in predicting the spread of a TSE disease among species. In the past, the species barrier was considered sufficiently strong to prevent casual transmission of prion disease from one species to another, yet recent evidence shows that BSE has been transmitted to $>15$ species, including humans, with 134 diagnosed cases to date (see www. dh.gov.uk/Home/fs/en). However, rather than being an indication of a weak species barrier, the permissive spread of BSE to a wide variety of species may reflect the level of BSE contamination in meat and bone meal. Experimentally, it has been possible to 
infect mice, calves, sheep, goats, and mink via both the parenteral and oral routes, although pigs are only susceptible to the parenteral route of infection (Ryder et al., 2000), with disease failing to occur in pigs monitored for 7 years after oral exposure (Wells et al., 2003). Despite a susceptibility of pigs to infection with BSE, there is no evidence of BSE disease in the domestic pig population, at least using the conventional method of detecting clinical signs confirmed by the histopathological analysis of brain sections or the presence of $\operatorname{PrP}^{\text {res }}$. However, recent evidence suggests that these criteria may not be sufficiently strict, because prion infection can be transmitted by animals that show no clinical signs of disease (Race and Chesebro, 1998; Hill et al., 2000) and by mice that show clinical signs but have no detectable $\mathrm{PrP}^{\text {res }}$ (Lasmezas et al., 1997). Because pigs are susceptible to BSE, it could be that subclinical infection, although undetected up until now, occurs in the domestic population. Given the resources and time scale (2-3 years before clinical signs appear in response to intracerebral BSE inoculation of pigs) (Ryder et al., 2000) required in studies on TSE diseases in large animals, so far much of the work on prions has been performed in mouse models (Dickinson et al., 1968; Scott et al., 1989; Collinge et al., 1995; Scott et al., 1997a). Transgenic mice expressing the $\operatorname{PrP}^{\mathrm{C}}$ of different species are generally easily infected with $\mathrm{PrP}^{\text {res }}$ from the particular species being tested and are useful species-specific models. Although $\mathrm{PrP}^{\text {res }}$ $\operatorname{PrP}^{\mathrm{C}}$ interaction occurs in a mouse cell background, these models have greatly contributed to understanding the species barrier. The use of Prnp null mice to create these species-specific models generally leads to a shorter incubation period (Telling et al., 1995; Scott et al., 1997a).

In this study, we developed several lines of transgenic mice expressing different levels of porcine $\operatorname{PrP}^{\mathrm{C}}\left(\mathrm{poPrP}^{\mathrm{C}}\right)$ in a Prnp null background to test for clinical or subclinical BSE infection in the pig population. Our ultimate goal was to gain additional insight into the species barrier between cattle and pigs, which appears to be stronger than barriers between the cow and mouse, cow and sheep, cow and goat, or cow and mink. We present evidence for a strong species barrier to the transmission of BSE from cattle to pigs. However, our most significant finding was the detection of subclinical infection in our transgenic mice expressing the porcine PrP gene, raising the possibility that pigs could harbor the BSE agent without showing the classic signs of its presence.

\section{Materials and Methods}

Plasmid constructs. The open reading frame (ORF) of the porcine PrP gene was isolated by PCR amplification from porcine DNA using primers that created a XhoI restriction enzyme site adjacent to the translation start and stop sites (5'-GATCTCGAGATGGTGAAAAGCCATA-3' and $5^{\prime}$-AAACTCGAGTCAGCCCACTATGAG-3'). The PCR fragment was subcloned into a $\mathrm{T}$-tailed vector, and the insert was sequenced to confirm five copies of the octapeptide repeat sequence and no difference in the inferred amino acid sequence with respect to previously sequenced porcine PrP genes (GenBank accession number L07623). The PrP ORF was excised from the T-tailed vector using the restriction enzyme XhoI, inserted into the expression vector MoPrP.Xho (Borchelt et al., 1996), which was also digested with $\mathrm{XhoI}$, and used to generate the transgenic mice.

Generation of transgenic mice. The MoPrP.Xho porcine transgene was excised from the plasmid vector using restriction endonuclease NotI to yield $12 \mathrm{~kb}$ DNA fragments. The construct was then purified using sodium chloride gradients (Fink, 1991). The DNA was resuspended in Tris-EDTA at a final concentration of $2-6 \mu \mathrm{g} / \mathrm{ml}$ and was then microinjected into 489 pronuclear-stage oocytes that were collected from superovulated $\mathrm{B}_{6 \mathrm{CBAF}}$ females mated with $129 /$ Ola males bearing a null mutation in the endogenous PrP gene (Manson et al., 1994). We then selected two porcine transgenic (poTg) lines, poTg027 and poTg001, from the initial heterozygous $\left[\operatorname{PrP}\right.$ mouse $\left.(\mathrm{mo})^{+/-} \mathrm{po}^{+/-}\right]$Tg lines and bred them to homozygosity in a murine $\operatorname{PrP}(\mathrm{moPrP})$ null background $\left(\operatorname{PrP} \mathrm{mo}^{-/-} \mathrm{po}^{+/+}\right)$, as described previously (Castilla et al., 2003). B6CBA $\times 129 /$ Ola mice and Prnp ${ }^{-1-}$ mice (hybrids) were used as controls in all of the infectivity experiments.

Screening of founders. DNA was prepared from tail biopsies (Hogan and Williams, 1981). The presence of the MoPrP.Xho porcine transgene was detected by PCR assay using primers specific for the mouse PrP exon 2 and porcine PrP ORF. The primers used were $5^{\prime}$-CCAGCCTCCACCACCATGTGGC-3' and 5'-CCACCACCTTGACCCCAGCC-3'. A PCR-amplified product of $326 \mathrm{nt}$ was taken to indicate $\mathrm{MoPrP}$.Xho porcine transgene. The absence of murine PrP ORF in transgenic mice was confirmed by PCR using the following primers: 5'-ATGGCGAACCTTGGCTACTGGC-3' and 5'-GATTATGGGTACCCCCTCCTTGG-3'.

BSE inocula. Three types of inocula were used: $\mathrm{BSE}_{1}$, a pool of material from 49 BSE-infected cattle brains (TSE/08/59) supplied by the Veterinary Laboratory Agency (VLA) (New Haw, Addlestone, Surrey, UK);

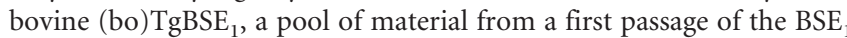
inoculum in bovine transgenic mice (line 110) generated in our laboratory (Castilla et al., 2003); and $\mathrm{BSE}_{2}$, material from one BSE-infected brainstem supplied by the VLA (RQ 225:PG1199/00). In second-passage experiments, we used an inoculum comprised of a $\mathrm{PrP}^{\text {res }}$-positive first-

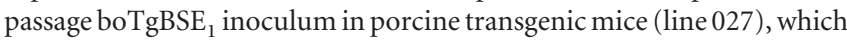
we denoted poTgBSE ${ }_{1}$, and two inocula comprised of $\operatorname{PrP}^{\text {res }}$-negative first-passage $\mathrm{BSE}_{1}$ or boTgBSE $\mathrm{E}_{1}$ inocula in porcine transgenic mice (line 001), denoted poTgBSE ${ }_{1}-\mathrm{N}_{1}$ and poTgBSE $\mathrm{N}_{1} \mathrm{~N}_{2}$, respectively. PBS was used as a negative control of inoculation. Brain homogenates $(10 \% \mathrm{w} / \mathrm{v})$ in sterile $\mathrm{Ca}^{2+}$ - and $\mathrm{Mg}^{2+}$-free PBS were prepared by mechanical homogenization (OMNI International, Warrenton, VA). To minimize the risk of bacterial infection, all of the inocula were preheated for $10 \mathrm{~min}$ at $70^{\circ} \mathrm{C}$ before their use in mice.

Infection experiments. Groups of 5-15 mice (6-7 weeks of age and weighing $\sim 20 \mathrm{gm}$ ) were inoculated in the right parietal lobe using a 25 gauge disposable hypodermic needle to deliver $20 \mu \mathrm{l}$ of $10 \%$ brain homogenate to each animal. The animals were culled for ethical reasons after detecting the following signs of disease progression: waddling gait, rough coat, dullness about the head, jumpy behavior, flattened back, sticky eye discharge, weight loss, and hunched position. When the animals were killed, brain specimens were obtained for identification of the typical histopathological signs of spongiform degeneration and the detection of PrP ${ }^{\text {res }}$ deposits by Western blotting and immunohistochemistry (IHC).

Histopathology and immunohistochemistry. Brains were prepared as described previously (Castilla et al., 2003), and stained sections were examined from (1) the medulla oblongata at the level of the obex and the pontine area, (2) the cerebellum, (3) the diencephalon, including the thalamus, (4) the hippocampus, and (5) the cerebral cortex.

The avidin-biotin-peroxidase complex technique was used for the immunohistochemical detection of $\mathrm{PrP}^{\text {res }}$ and glial fibrillary acid protein (GFAP), as described previously (Castilla et al., 2003). Tissue sections were prepared as described previously (Castilla et al., 2003) and then incubated overnight at $4^{\circ} \mathrm{C}$ with primary $6 \mathrm{H} 4$ monoclonal antibody $(\mathrm{mAb})$ (Prionics, Schlieren, Switzerland) or $2 \mathrm{~A} 11 \mathrm{mAb}$ (Brun et al., 2004) diluted 1:400 in PBS. The slides were then treated with the secondary antibody and developed according to a previously described procedure (Castilla et al., 2003). Brain sections for GFAP labeling were incubated overnight at $4^{\circ} \mathrm{C}$ with primary anti-GFAP polyclonal antibody (Dako, High Wycombe, UK) diluted 1:500 in PBS. Goat anti-rabbit IgG (Vector Laboratories, Burlingame, CA) diluted 1:200 in PBS was used as the secondary antibody. The procedure was then continued as described above.

Western blotting. $\mathrm{PrP}^{\mathrm{C}}$ expression in transgenic mice was determined as described previously (Castilla et al., 2003). A 1\% brain homogenate was used to quantify the $\mathrm{PrP}^{\text {res }}$ content of the different inocula used. All of the negative homogenates were solubilized v/v in 10\% Sarcosyl and centrifuged for $2 \mathrm{hr}$ at $100,000 \times \mathrm{g}$. The pellet was resuspended to concentrate the samples 10 times. For the immunoblotting experiments, mAbs 2A11 and FH11 (Foster et al., 1996) were used at 1:2000 and 1:500 


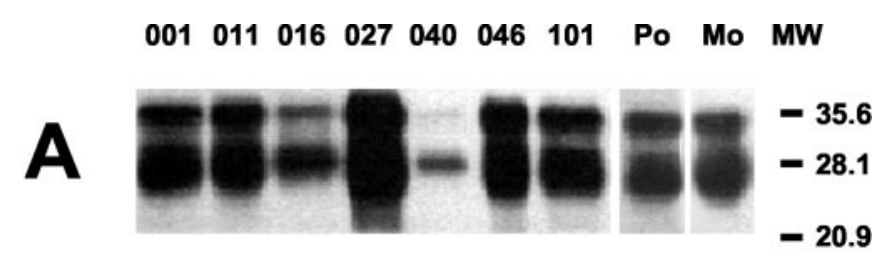

B

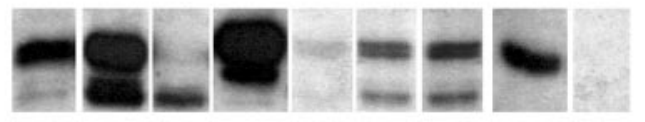

$-35.6$

$-28.1$

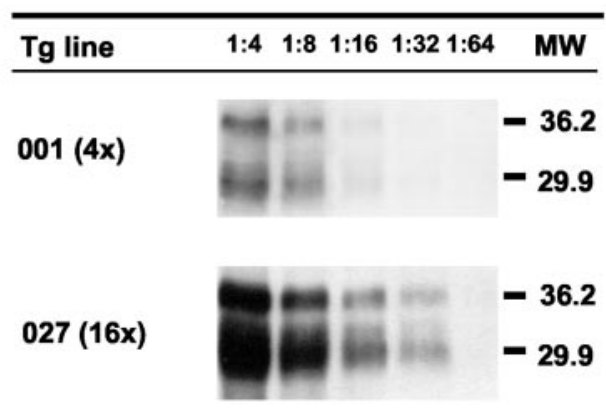

\section{\begin{tabular}{llllll}
\hline Species & $1: 1$ & $1: 2$ & $1: 4$ & $1: 8$ & $1: 16$
\end{tabular}}

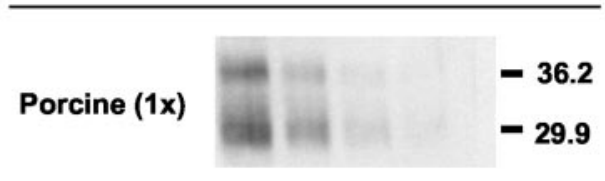

Figure 1. Expression of the porcine PrP protein in heterozygous $\left(\mathrm{mo}^{+/-} \mathrm{po}^{+/-}\right)$poTg lines. Immunoblotting of transgenic mouse brain extracts from Tg lines $001,011,016,027,040$, 046 , and 101 using the monoclonal antibodies $2 \mathrm{~A} 11$ ( $A$ ) or FH11 (B). Serial dilution of homozygous $\left(\mathrm{mo}^{-1-} \mathrm{po}^{+/+}\right)$poTg mouse lines $(001$ and 027$)$ and porcine brain homogenates were analyzed by Western blotting using monoclonal antibody $2 \mathrm{~A} 11$ ( ( ). Po, Porcine brain extract; Mo, B6CBA $\times 129 /$ la mouse brain extract. Equivalent amounts of protein were loaded onto each lane. Relative molecular mass is given in kilodaltons. MW, Molecular weight.

dilutions, respectively. Immunocomplexes were detected with horseradish peroxidase-conjugated anti-mouse IgG (Sigma, St. Louis, MO). The immunoblots were developed under conditions of enhanced chemiluminescence (Amersham Biosciences, Arlington Heights, IL).

\section{Results}

Porcine $\operatorname{PrP}^{\mathrm{C}}$ expression in transgenic mouse lines

Seven different lines (founders) each of $\operatorname{poPrP}^{\mathrm{C}}$ and $\mathrm{moPrP}^{\mathrm{C}}$ heterozygous transgenic mice ( $\mathrm{PrP} \mathrm{mo}^{+/-} \mathrm{po}^{+/-}$) were obtained (Fig. $1 A$ ). Because the porcine and murine PrPs were indistinguishable according to their relative electrophoretic mobilities, their expression was confirmed using the FH11 mAb, which fails to recognize endogenous moPrP (Fig. $1 B$ ). We then selected two lines and bred them to homozygosity $\left(\mathrm{mo}^{-/-} \mathrm{po}^{+/+}\right)$. The absence of the murine PrP gene was determined by PCR (data not shown). $\operatorname{PrP}^{\mathrm{C}}$ expression levels in the homozygous mouse lines poTg001 and poTg027 were fourfold and 16-fold, respectively, the levels observed in pig brain homogenates (Fig. 1C).

Behavior and phenotype of all transgenic lines obtained were identical to normal mice, although at later times in the mouse lifespan it was possible to observe some degree of motor impairment, regardless of bovine PrP expression level, mainly affecting the hind limbs. At later times, these mock-inoculated animals also showed focal vacuolation of the CNS. The development of this neurological syndrome was dependent on transgene dosage. For example, homozygous po001Tg mice developed the disease at $\sim 525 \mathrm{~d}$ of age, whereas heterozygous po001Tg mice became ill at $600 \mathrm{~d}$. In the case of po027Tg mice, homozygotes developed disease at $\sim 400 \mathrm{~d}$ of age, whereas heterozygotes became ill at $500 \mathrm{~d}$. A phenomenon similar to the one found in our poPrP transgenic mice was reported previously for Syrian hamster PrPexpressing transgenic mice (Westaway et al., 1994). This phenotype was mainly attributed to the high levels of $\operatorname{PrP}^{\mathrm{C}}$ expression ( $\geq 30$-fold the hamster expression levels) in the absence of detectable $\mathrm{PrP}^{\text {res }}$ accumulation.

\section{Susceptibility of poTg mice to BSE prions}

PoTg001 and poTg027 mice inoculated with the BSE $\mathrm{B}_{1}$ inoculum showed survival times similar to those seen for PBS-inoculated controls (Table 1). $\mathrm{PrP}^{\text {res }}$ accumulation was nondetectable by Western blotting or IHC in any of the inoculated animals (see Figs. $\left.2 A, 4 B_{1,4}\right)$. However, all of the poTg001 and poTg027 mice inoculated with boTgBSE or $_{1} \mathrm{BSE}_{2}$ (Fig. 3) showed clinical signs of BSE, and some of these mice were found to have amounts of $\mathrm{PrP}^{\text {res }}$ detectable by Western blotting and IHC. After inoculation with $\mathrm{BSE}_{2}$, both poTg027 and poTg001 mice showed an $\sim 100 \mathrm{~d}$ reduction in survival time compared with control inoculations. Moreover, $\operatorname{PrP}^{\text {res }}$ was detectable by immunoblotting (Fig. 2) and IHC (Fig. $4 C_{1,4}$ ) in one of five poTg027 mice and one of six poTg001 mice. Similarly, inoculation of poTg027 mice with boTgBSE 1 gave rise to a $100 \mathrm{~d}$ reduction in survival time with respect to $\mathrm{PBS}$-inoculated controls, and the $\mathrm{PrP}^{\text {res }}$ protein could be detected by Western blotting (Fig. $2 A$ ) in one of the five infected mice. Bovine $\mathrm{TgBSE}_{1}$ inoculation of poTg001 mice led to an $\sim 60 \mathrm{~d}$ reduction in survival time compared with controls (Table 1), but it was not possible to detect $\mathrm{PrP}^{\text {res }}$ in any of the six infected mice (data not shown).

To confirm the infectivity of the inocula used in these experiments, we also inoculated boTg mice (Castilla et al., 2003) and nontransgenic mice. All of the inocula $\left(\mathrm{BSE}_{1}, \mathrm{boTgBSE}_{1}\right.$, and $\mathrm{BSE}_{2}$ ) were equally competent at transmitting BSE to boTg110 mice (Figs. $2 A, 4 C$, Table 1 ). The $\mathrm{BSE}_{1}$ inoculum was able to infect 5 of 12 non-Tg mice, as determined by the presence of $\mathrm{PrP}^{\mathrm{res}}$ (data not shown and Table 1). These data confirm that all of the inocula were capable of efficiently transmitting BSE, including the low-dose $\mathrm{BSE}_{1}$ inoculum that was found to successfully infect both wild-type mice and transgenic mice expressing bovine PrP.

We then performed a series of second-passage experiments in which brain material from poTg027 mice showing detectable amounts of $\mathrm{PrP}^{\text {res }}$ in response to boTgBSE $\mathrm{F}_{1}$ inoculation was used to infect poTg001, poTg027, and boTg110 mice. The signal observed by Western blotting of porcine $\mathrm{PrP}^{\text {res }}$ used as the inoculum (denoted poTgBSE ( $_{1}$ ) was similar to that of the boTgBSE $\mathrm{T}_{1}$ and

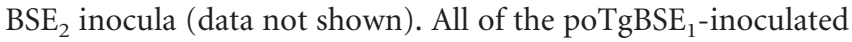
poTg mice proved positive for porcine $\mathrm{PrP}^{\text {res }}$ by Western blotting and showed considerably reduced survival times compared with their counterparts infected with first-passage inocula (Table 1), indicating species barrier abrogation (Fig. 2B). Bovine Tg110 mice were also efficiently infected with the poTgBSE $\mathrm{T}_{1}$ inoculum, with $100 \%$ of inoculated boTg110 mice showing bovine $\operatorname{PrP}^{\text {res }}$ with Western blotting (Table 1). The $\mathrm{PrP}^{\text {res }}$ patterns of the three different inocula used were identical according to Western blotting analysis. However, as expected, the $\operatorname{PrP}^{\text {res }}$ pattern observed after the first passage in poTg mice clearly differed from the $\mathrm{PrP}^{\text {res }}$ pattern of the inocula used, confirming the change of PrP species. The new pattern was maintained in subsequent passages of inoculation in 
Table 1. Susceptibility of porcine PrP transgenic mice to BSE and PSE prions

\begin{tabular}{|c|c|c|c|c|c|c|}
\hline Recipient & Inoculum & Transgene expression $^{a}$ & Death (days \pm SEM) & TSE clinical signs ${ }^{c}$ & $\operatorname{PrP}^{\text {res }}(+)^{d}$ & $(\%)$ \\
\hline \multicolumn{7}{|l|}{ First passage } \\
\hline Non- $\operatorname{Tg}(\mathrm{B} 6 \times \mathrm{CBA} \times 1290 \mathrm{la})$ & $\mathrm{BSE}_{1}$ & $1 \times^{b}$ & $656 \pm 30$ & $5 / 12$ & $5 / 12$ & (42) \\
\hline Non-Tg $\left(p r n p^{-I-}\right)$ & $\mathrm{BSE}_{1}$ & $0 \times^{b}$ & $688 \pm 35$ & $0 / 6$ & $0 / 6$ & (0) \\
\hline boTg110 $+1+$ & $\mathrm{BSE}_{1}$ & $8 \times$ & $326 \pm 18$ & $13 / 13$ & $13 / 13$ & $(100)$ \\
\hline boTg110 & $\mathrm{BSE}_{1}$ & $4 \times$ & $359 \pm 15$ & $11 / 11$ & $11 / 11$ & $(100)$ \\
\hline poTg001 ${ }^{+/+}$ & $\mathrm{BSE}_{1}$ & $4 \times$ & $587 \pm 17$ & $6 / 6$ & $0 / 6$ & (0) \\
\hline poTg001 ${ }^{+/-}$ & $\mathrm{BSE}_{1}$ & $2 \times$ & $617 \pm 31$ & $10 / 10$ & $0 / 10$ & (0) \\
\hline poTg027 $7^{+/+}$ & $\mathrm{BSE}_{1}$ & $16 \times$ & $411 \pm 16$ & $9 / 9$ & $0 / 9$ & (0) \\
\hline $\mathrm{poTg} 027^{+/-}$ & $\mathrm{BSE}_{1}$ & $8 \times$ & $572 \pm 23$ & $14 / 14$ & $0 / 14$ & (0) \\
\hline boTg110 & $\mathrm{BSE}_{2}$ & $8 \times$ & $308 \pm 5$ & $5 / 5$ & $5 / 5$ & $(100)$ \\
\hline poTg001 ${ }^{+/+}$ & $\mathrm{BSE}_{2}$ & $4 \times$ & $488 \pm 4$ & $6 / 6$ & $1 / 6$ & (17) \\
\hline poTg027 $7^{+/+}$ & $\mathrm{BSE}_{2}^{2}$ & $16 \times$ & $294 \pm 14$ & $5 / 5$ & $1 / 5$ & $(20)$ \\
\hline boTg110 & boTgBSE $_{1}$ & $8 \times$ & $291 \pm 18$ & $6 / 6$ & $6 / 6$ & $(100)$ \\
\hline poTg001 ${ }^{+/+}$ & boTgBSE $_{1}$ & $4 \times$ & $528 \pm 17$ & $6 / 6$ & $0 / 6$ & (0) \\
\hline poTg027 $1+$ & $\mathrm{boTgBSE}_{1}$ & $16 \times$ & $310 \pm 48$ & $5 / 5$ & $1 / 5$ & $(20)$ \\
\hline \multicolumn{7}{|l|}{ Second passage } \\
\hline Non- $\operatorname{Tg}(B 6 \times C B A \times 1290 l a)$ & poTgBSE $_{1}$ & $1 \times$ & $>400$ & $5^{e}$ & $5^{e}$ & \\
\hline boTg110 $+/+$ & poTgBSE $_{1}$ & $8 \times$ & $367 \pm 17$ & $5 / 5$ & $5 / 5$ & $(100)$ \\
\hline poTg001 ${ }^{+/+}$ & $\mathrm{poTgBSE}_{1}$ & $4 \times$ & $198 \pm 4$ & $15 / 15$ & $15 / 15$ & (100) \\
\hline poTg027 $7^{+/+}$ & poTgBSE $_{1}$ & $16 \times$ & $177 \pm 9$ & $6 / 6$ & $6 / 6$ & $(100)$ \\
\hline Non- $\operatorname{Tg}($ B6 $\times$ CBA $\times 1290 \mathrm{la})$ & poTgBSE ${ }_{1}-\mathrm{N}_{1}^{*}$ & $1 \times$ & $>600$ & $9^{e}$ & $9^{e}$ & \\
\hline boTg $110^{+/+}$ & poTgBSE ${ }_{1}-\mathrm{N}_{1}$ & $8 \times$ & $>500$ & $5^{e}$ & $5^{e}$ & \\
\hline poTg001 ${ }^{+/+}$ & $\mathrm{poTgBSE}_{1}-\mathrm{N}_{1}$ & $4 \times$ & $406 \pm 23$ & $9 / 9$ & $0 / 9$ & (0) \\
\hline $\mathrm{poTg}_{001}{ }^{+/+}$ & $\mathrm{poTgBSE}_{1}-\mathrm{N}_{2}{ }^{* *}$ & $4 \times$ & $269 \pm 23$ & $6 / 6$ & $2 / 6$ & (33) \\
\hline boTg110 $10^{+/+}$ & PBS-inoculated & $8 \times$ & $599 \pm 27$ & $0 / 5$ & $0 / 5$ & $(0)$ \\
\hline poTg001 $1^{+1+}$ & PBS-inoculated & $4 \times$ & $585 \pm 18$ & $9 / 9$ & $0 / 9$ & $(0)$ \\
\hline poTg $027^{+/+}$ & PBS-inoculated & $16 \times$ & $421 \pm 35$ & $5 / 5$ & $0 / 5$ & $(0)$ \\
\hline
\end{tabular}

${ }^{a}$ Relative to cattle or porcine PrP expression.

${ }^{b}$ Corresponding to murine PrP gene expression.

$c, d$ Number of animals with clinical signs or Prp res with respect to the number of inoculated animals.

estill alive.

${ }^{+/+}$or $^{+/-}$, Homozygous or heterozygous for the bovine or porcine prnp gene. All transgenic animals are murine Pmp ${ }^{-1-}$.

*Inoculum from BSE $_{1}$-infected poTg mice diagnosed as negative by Western blot.

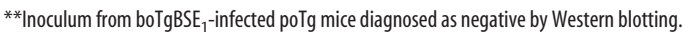

poTg mice (data not shown). These data are consistent with other studies using ovine, murine, and bovine PrP transgenic mice (Scott et al., 1999; Vilotte et al., 2001; Castilla et al., 2003).

Given that poTg mice are susceptible to BSE infection, we reasoned that poTg mice inoculated with $\mathrm{BSE}_{1}$ could become subclinically infected. To test this hypothesis, we used the poTg001 mouse line to test poTg mice previously scoring negative for $\mathrm{PrP}^{\text {res }}$ and clinical signs of BSE. To this end, the inocula poTgBSE $_{1}-\mathrm{N}_{1}$ and poTgBSE ${ }_{1}-\mathrm{N}_{2} \quad\left(\mathrm{BSE}_{1}{ }^{-}\right.$and boTgBSE ${ }^{-}$ inoculated poTg001 mice not producing $\mathrm{PrP}^{\text {res }}$, respectively) were used in second-passage experiments. None (0 of 9) of the poTgBSE ${ }_{1}-\mathrm{N}_{1}$-inoculated poTg001 mice scored positive for $\mathrm{PrP}^{\mathrm{res}}$ by Western blotting (Table 1 ), but survival times were reduced from $587 \pm 17$ to $406 \pm 23 \mathrm{~d}$, indicating the infectivity of the inoculum. In contrast, the poTgBSE ${ }_{1}-\mathrm{N}_{2}$-inoculated poTg001 mice showed neurological signs of disease and had a survival time that was shortened by $269 \pm 23 \mathrm{~d}$; in addition, two of six $(33 \%)$ mice scored positive for $\mathrm{PrP}^{\text {res }}$ by Western blotting (Table 1). Thus, clinically healthy $\mathrm{PrP}^{\text {res }}$-negative poTg mice were able to replicate porcine-adapted BSE and were also competent at transmitting the disease.

\section{Histopathology and immunohistochemistry of BSE-inoculated mouse brains}

In agreement with the biochemical data, histopathological and immunohistological studies showed no $\mathrm{PrP}^{\text {res }}$ deposition in brain sections from $\mathrm{BSE}_{1}$-inoculated poTg001 mouse lines, which were indistinguishable from PBS-inoculated poTg001 brain sections (Fig. $4 A, B$ ). We observed no differences between
BSE $_{1}$-inoculated and PBS-inoculated animals killed at 520-730 d of age. In mice that were successfully infected with the $\mathrm{BSE}_{2}$ or boTgBSE $_{1}$ inocula, granular neuronal cytoplasmic and perineuronal labeling (Fig. $4 C_{4}$ ) and punctate neuropil labeling (Fig. $4 C_{1}$ ) appeared as the most common histological patterns. Severe vacuolation was always accompanied by astrocytic gliosis. Astrocyte prolongations enveloped the vacuoles. Occasionally, the astrocyte cytoplasm was enlarged (Fig. $4 C_{2,5}$ ).

In second-passage studies, histopathological signs and IHC findings were similar to those noted in the first-passage experiments using $\mathrm{BSE}_{2}$ (Fig. 4C,B). In comparative IHC studies of

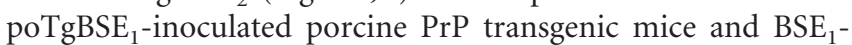
inoculated bovine PrP transgenic mice (Castilla et al., 2003), similar characteristics were observed (Fig. 5B,C). These histopathological findings essentially included vacuolation of the neuropil and an astrocyte response. These changes, along with the $\mathrm{PrP}^{\mathrm{res}}$ deposition detected by immunohistochemistry, resembled those reported in BSE (Wells and Wilesmith, 1995) and in pigs inoculated with BSE by intravenous, intraperitoneal, and intracerebral routes (Ryder et al., 2000).

\section{Discussion}

The transgenic mouse lines developed expressed the porcine PrP transgene at different levels. This is characteristic of random transgene integration in the mouse genome by the microinjection technique. Given that high expression levels promote reduced incubation times for heterologous and homologous prion propagation in mice (Scott et al., 1997b; Castilla et al., 2003), we selected two poTg 


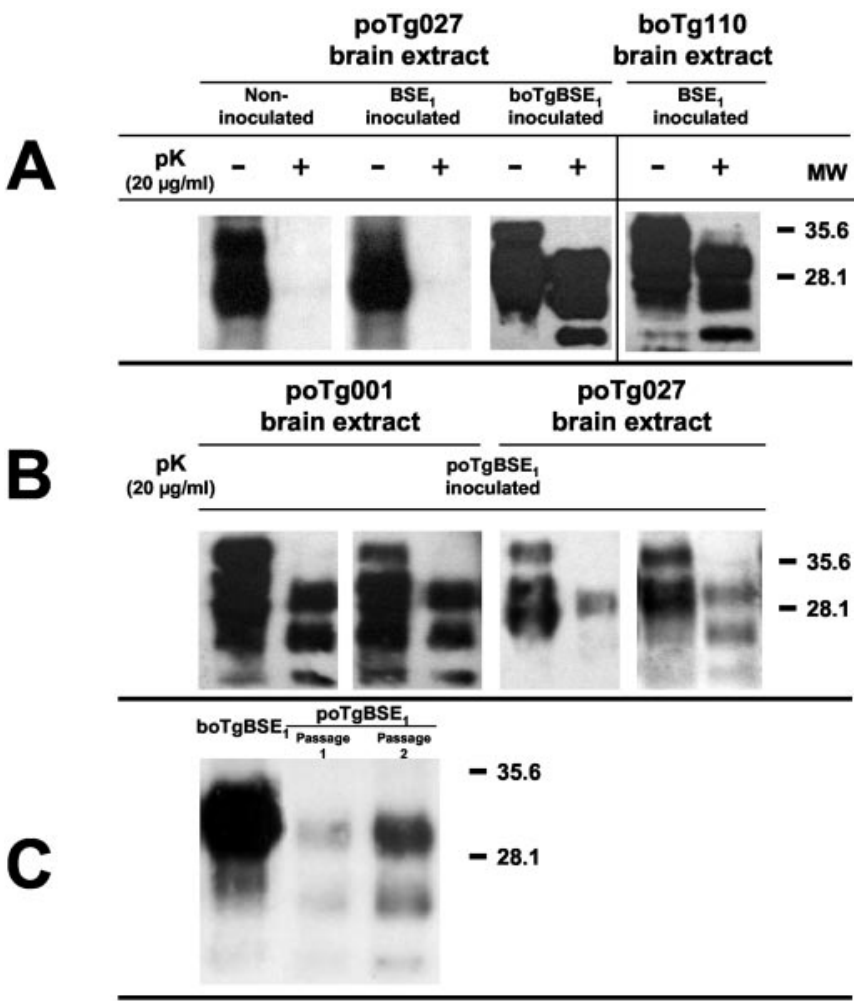

Figure 2. Detection of the PrP res protein in inoculated poTg mice. $A$, Western blot of poTg027 brain extracts from mice inoculated intracerebrally with the different inocula. The PrP res protein was only detected in one of five bo $\mathrm{TgBSE}_{1}$-inoculated mice. $B$, Western blot of poTg001 and poTg027 brain extracts of mice inoculated intracerebrally with the poTgBSE $\mathrm{F}_{1}$ inoculum. All of the mice inoculated showed PrP res. C, Western blot of boTgBSE, poTgBSE ${ }_{1}$ passage 1, and poTgBSE 1 passage 2 brain homogenates digested with PK. Monoclonal antibody 2A11 was used at a 1:2000 dilution. Relative molecular mass is given in kilodaltons. MW, Molecular weight; $\mathrm{pK}$, proteinase $\mathrm{K}$.

lines, poTg001 and poTg027, expressing fourfold and 16-fold, respectively, the levels of PrP protein found in pig brain.

We observed that mice expressing higher levels of poPrP spontaneously developed clinical signs. A similar neurological syndrome was described previously by Westaway et al. (1994) in older Tg PrP mice expressing high levels of hamster, ovine, or murine PrP transgenes. This phenomenon may be related to the observed toxicity of overexpressed PrP in certain cell lines, which suggests that lack of physiological $\mathrm{PrP}^{\mathrm{C}}$ expression may render pathogenic in mice. However, the lifespan of poTg027 mice was much longer than the time needed by porcine prions to propagate in these animals, and the confirmation of infection could be tested using proteinase $\mathrm{K}(\mathrm{PK})$-resistant studies. In none of the cases did the noninoculated animals presenting late clinical signs show PKresistant protein.

We observed substantial evidence of subclinical BSE infection in our poTg mice. PoTg mice inoculated with $\mathrm{BSE}_{1}$ showed no clinical signs of BSE or detectable $\mathrm{PrP}^{\text {res }}$ protein. However, subsequent passage of brain homogenates from these mice indicated the high level of infectivity of one of these animals. The presence of subclinical infection was particularly evident when we used the poTgBSE ${ }_{1}-\mathrm{N}_{2}$ inoculum (first-passage boTgBSE in $_{1}$ poTg $\operatorname{PrP}^{\text {res }}$ negative mice), which led to a mean incubation time of $269 \mathrm{~d}$ and to $\operatorname{PrP}^{\text {res }}$ that was detectable by Western blotting in two of six mice. The presence of subclinical infection has been reported in other species (Race and Chesebro, 1998; Hill et al., 2000). Although there is no evidence of clinical BSE disease in the domestic pig population, pigs are susceptible to BSE, and our observations
Inoculum

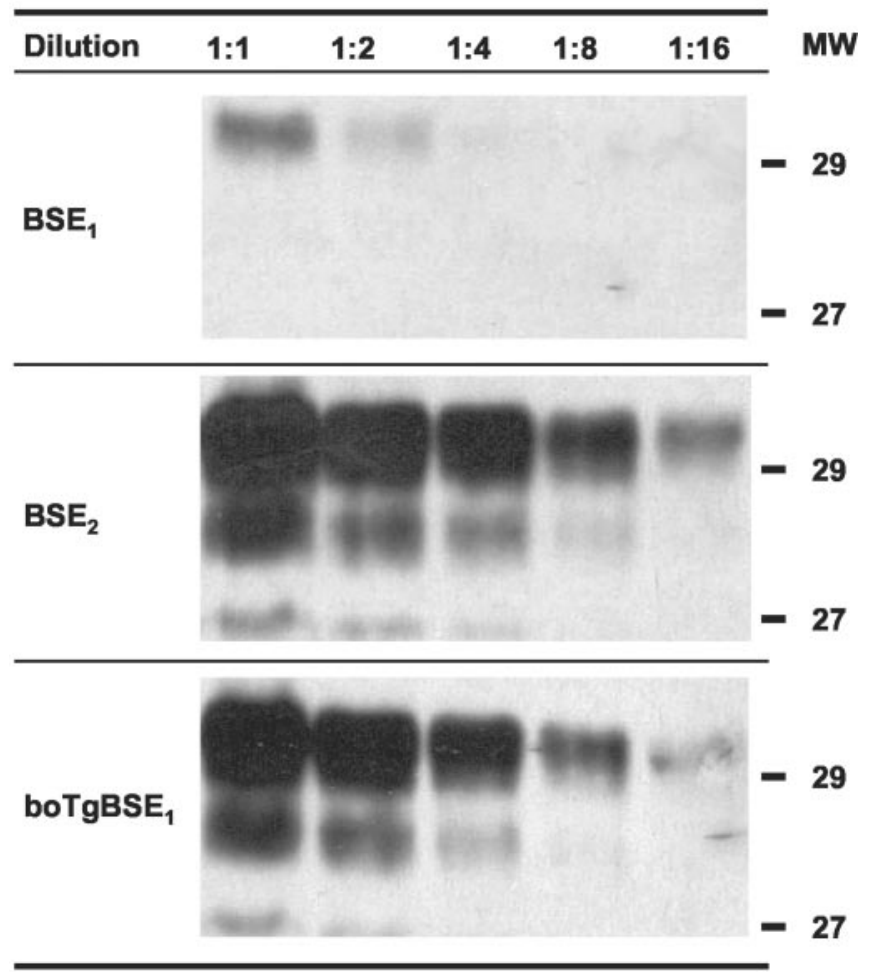

Figure 3. Quantification of the $\mathrm{Pr} \mathrm{P}^{\text {res }}$ content of the different inocula used. Serial dilution of $1 \%$ brain homogenates was Western blotted using mAb $2 \mathrm{~A} 11 . \mathrm{BSE}_{1}$, A pool of brainstem material from 49 BSE-infected cattle (TSE/08/59) supplied by the VLA; boTgBSE 1 , a pool of material from bovine transgenic mice (line 110) infected with first-passage BSE $_{1}$ inoculum generated in our laboratory; $\mathrm{BSE}_{2}$, brainstem material from one BSE-infected cow supplied by the VLA. Monoclonal antibody 2A11 was used at a 1:2000 dilution. Relative molecular mass is given in kilodaltons. MW, Molecular weight.

raise the possibility of subclinical infection occurring in pigs. The poTg model could be used as an assay for subclinical infection in suspected cases of prion disease in pigs.

Three inocula (Fig. 3) were used to infect the poTg mice. These inocula are known to efficiently infect transgenic mice expressing the bovine PrP gene (boTg110 line) (Castilla et al., 2003). We used the same vector to express the porcine and bovine PrP genes under the mouse PrP promoter. In the boTg110 model, increasing the $\operatorname{PrP}^{\text {res }}$ titer had no effect on the incubation time. When the low-dose $\mathrm{BSE}_{1}$ inoculum was tested in a normal mouse line, the animals showed neurological signs of disease, and 5 of 12 (42\%) scored positive for $\operatorname{PrP}^{\text {res }}$. These data indicate that the $\mathrm{BSE}_{1}$ inoculum can cross the bovine-murine species barrier, although the expression level of the mouse $\operatorname{PrP}^{\mathrm{C}}$ is approximately half that shown by our transgenic lines.

However, the low-dose $\mathrm{BSE}_{1}$ inoculum provided evidence for a strong bovine-porcine species barrier, because it produced no signs of infection in the poTg001 or poTg027 mice. Survival times were unchanged compared with those observed in control PBSinoculated poTg001 or poTg027 mice, and no $\mathrm{PrP}^{\text {res }}$ was detected in any of the 39 inoculated mice (Table 1). In contrast, the higher

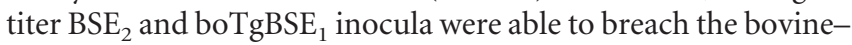
porcine species barrier, and $\operatorname{PrP}{ }^{\text {res }}$ was detected in 3 of 22 infected poTg mice (14\%). Additional evidence for the bovine-porcine species barrier was obtained in second-passage transmission from BSE-infected poTg mice. The survival time dropped from 488 to 198 d postinoculation (dpi) for poTg001 and from 300 to 


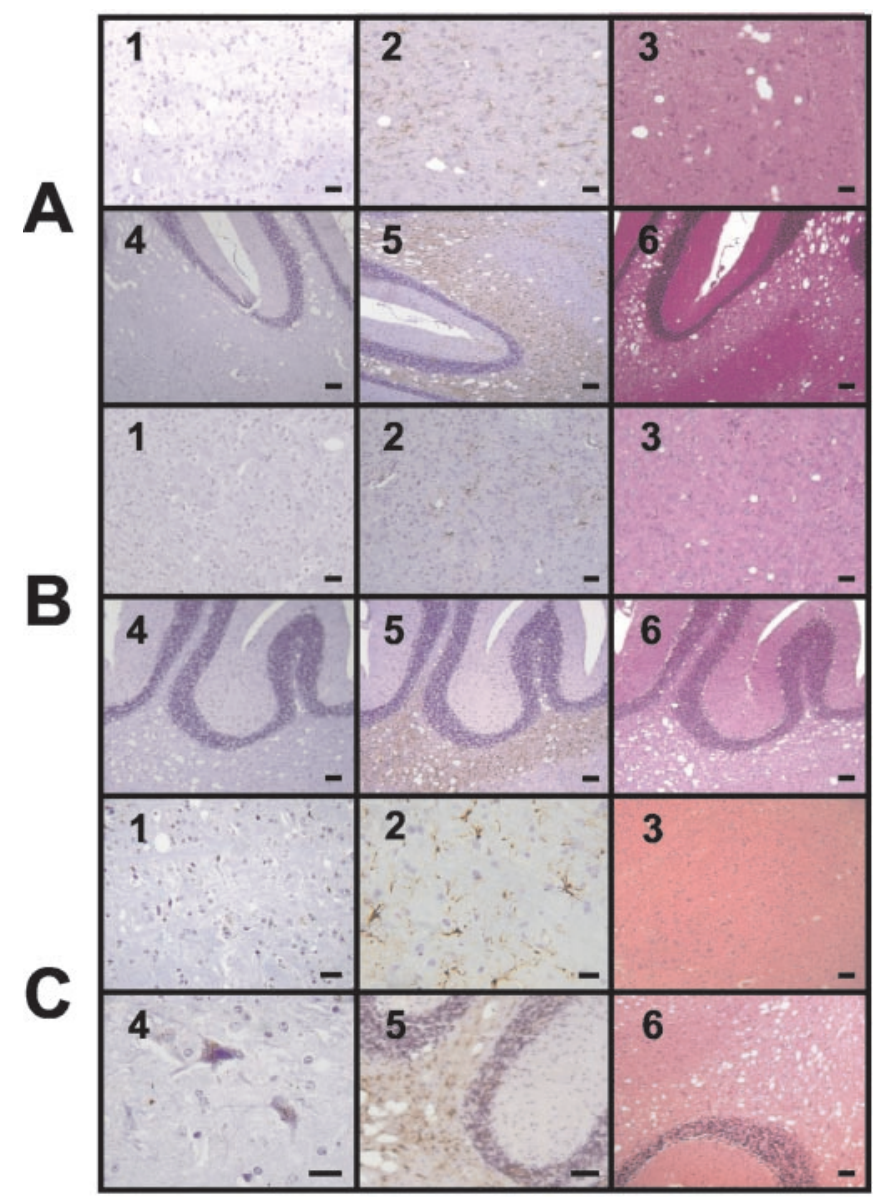

Figure 4. Neuropathological appearance of brain sections of PBS-inoculated poTg001 mice (540 dpi; $A$ ), BSE 1 -inoculated poTg001 mice (540 dpi; B), and BSE--inoculated poTg001 mice ( $488 \mathrm{dpi} ;$ (). The numbers $1-3$ correspond to sections of the thalamus, and $4-6$ correspond to cerebellar sections. 3, 6, Hematoxylin-eosin staining; 2, 5, anti-GFAP immunostaining; 1, 4, $2 \mathrm{~A} 11 \mathrm{mAb}$ immunostaining. Note the fine granular immunolabeling in the neuropil and glial pattern in the thalamus $\left(C_{1}\right)$ and granular immunolabeling in neuronal bodies of the cerebellar nuclei $\left(C_{4}\right)$. Scale bars, $50 \mu \mathrm{m}$.

177 dpi for the poTg027 mice. The presence of a strong barrier may explain the resistance to infection shown by pigs during the BSE epidemic in the United Kingdom.

Contrary to the strong species barrier observed when poTg mice were inoculated with BSE, there was little evidence of a species barrier in the opposite direction (i.e., when we infected boTg110 mice with poTgBSE ${ }_{1}$ ). All of the boTg mice infected with this inoculum scored positive for $\mathrm{PrP}^{\text {res }}$, suggesting that the barrier has different difficulty levels depending on the direction of the infection. Western blotting analysis confirmed that the $\mathrm{PrP}^{\text {res }}$ observed in the bo110Tg mice displayed the same pattern (band size, glycoform ratio) as the boTgBSE ${ }_{1}$ or $\mathrm{BSE}_{1}$ inocula but a pattern that is different from that of the newly generated porcine prion (po027Tg) (Fig. 2C). A characteristic feature of the BSE prion is that it retains its biological properties when transmitted to other species such as humans (Collinge and Rossor, 1996; Collinge et al., 1996; Will and Zeidler, 1996; Scott et al., 1999), sheep (Foster et al., 1993, 2001), or mice (Fraser et al., 1992; Lasmezas et al., 1997). Thus, the lack of a strong species barrier observed for transmission in the direction of pig to cow might be explained if the initial BSE inoculum infecting the pig confers BSElike properties on the porcine prion, although the primary amino acid sequence of this prion is the porcine one. Alternatively, these results could be explained as follows: (1) the bovine PrP is a very

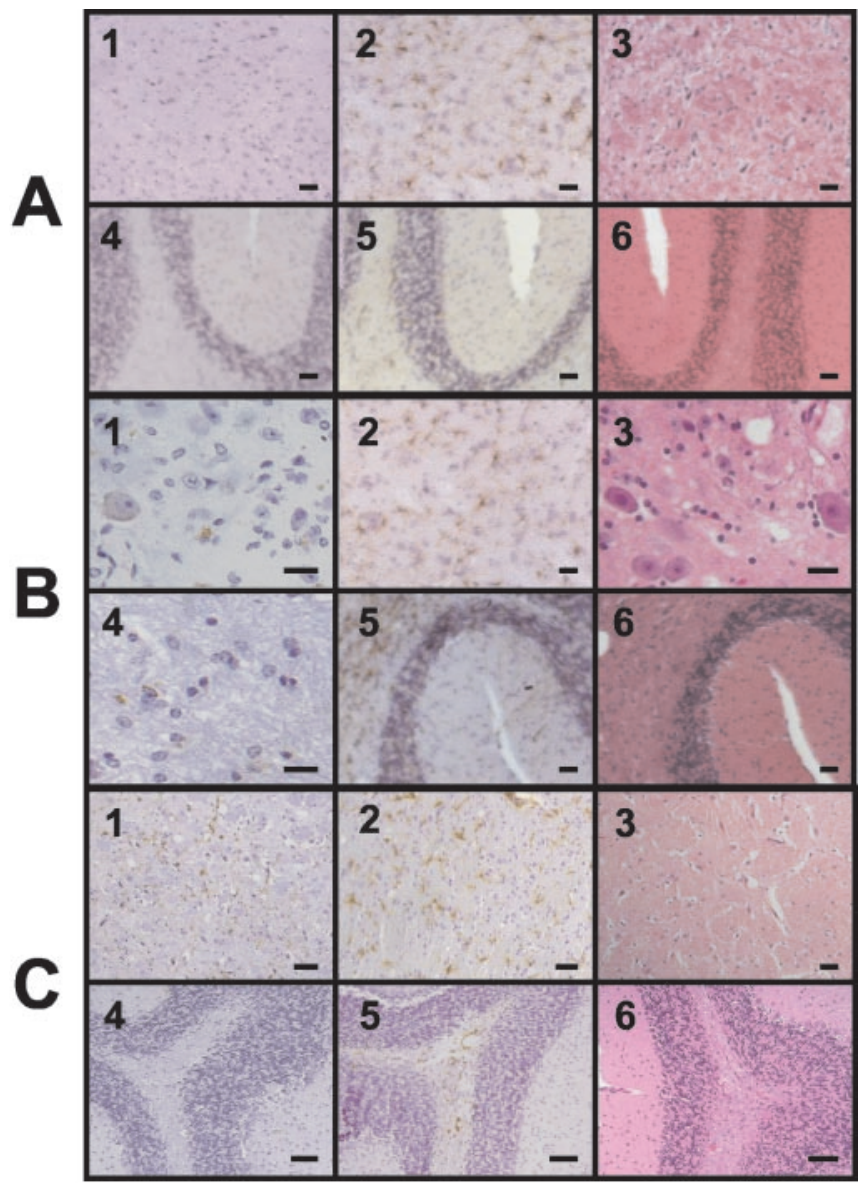

Figure 5. Neuropathological appearance of brain sections of $P B S$-inoculated poTg001 mice (180 dpi; A), poTgBSE -inoculated poTg001 mice (180 dpi; B), and BSE -inoculated boTg110 mice ( $250 \mathrm{dpi} ; \mathrm{C}$ ). The numbers $1-3$ correspond to sections of the thalamus, and $4-6$ correspond to cerebellar sections. 3, 6, Hematoxylin- eosin staining; 2, 5, anti-GFAP immunostaining; 1, 4, $2 \mathrm{~A} 11 \mathrm{mAb}$ immunostaining. Note the fine granular immunolabeling in the neuropil and glial pattern in the thalamus $\left(B_{1}\right)$ and granular immunolabeling in neuronal bodies of the cerebellar nuclei $\left(B_{4}\right)$. Scale bars, $50 \mu \mathrm{m}$.

permissive protein, more easily transformed by other heterologous prions or (2) the new porcine prion is highly infectious compared with others. This second possibility will be studied using other transgenic mice expressing ovine and human PrP.

The species barrier is related to amino acid sequence differences in the globular domain of the PrP protein, which undergoes a conformational change from $\alpha$-helix to $\beta$-pleated sheet structures. The porcine PrP shows the most unique amino acid sequence (5) in this domain when compared with the mouse, cow, sheep, hamster, and human PrP sequences. Figure 6 compares the globular domains of porcine, bovine, and mouse PrP. It may be observed that four of the five unique amino acids occur in helix 3 , and that there are two additional differences in this helix between the porcine and bovine sequence, I to $\mathrm{V}$ and $\mathrm{R}$ to $\mathrm{K}$. The $\mathrm{K}$ residue is known to alter the length and quality of definition of helix 3 (Calzolai et al., 2000), and it is possible that this combination of amino acid variants alters the structure of helix 3 sufficiently to inhibit interactions between porcine $\operatorname{PrP}^{\mathrm{C}}$ and $\operatorname{PrP}^{\mathrm{res}}$. Nuclear magnetic resonance analysis indicates that the global architecture of this region is similar for all species analyzed to date (Riek et al., 1998; Lopez Garcia et al., 2000; Zahn et al., 2000), but individual amino acid changes have been shown to affect local conformation or surface charge (Lopez Garcia et al., 2000). These 

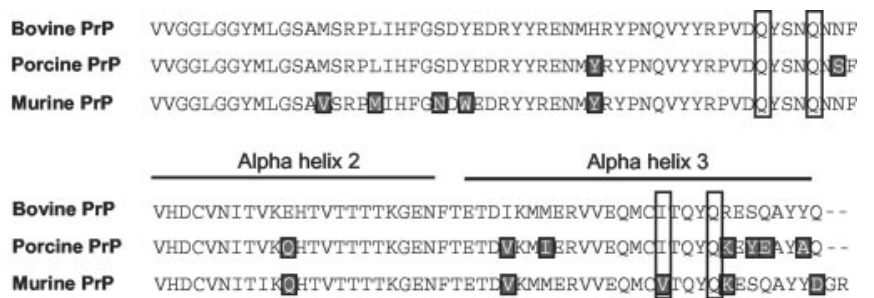

Figure 6. Alignments of amino acid sequences in bovine, porcine, and murine PrPs. White letters with gray shading represent amino acid changes with respect to the bovine sequence. Vertical boxes indicate the protein $X$ epitope.

subtle differences may be sufficient to strengthen or weaken a species barrier.

\section{References}

Borchelt DR, Davis J, Fischer M, Lee MK, Slunt HH, Ratovitsky T, Regard J, Copeland NG, Jenkins NA, Sisodia SS, Price DL (1996) A vector for expressing foreign genes in the brains and hearts of transgenic mice. Genet Anal 13:159-163.

Brun A, Castilla J, Ramírez MA, Prager K, Parra B, Salguero FJ, Shiveral D, Sánchez C, Sánchez-Vizcaíno JM, Douglas A, Torres JM (2004) Proteinase $\mathrm{K}$ enhanced immunorreactivity of the prion protein specific monoclonal antibody 2A11. J Neurosci Res 48:75-83.

Calzolai L, Lysek DA, Guntert P, von Schroetter C, Riek R, Zahn R, Wuthrich K (2000) NMR structures of three single-residue variants of the human prion protein. Proc Natl Acad Sci USA 97:8340-8345.

Castilla J, Gutiérrez Adán A, Brun A, Pintado B, Ramírez MA, Parra B, Doyle D, Rogers M, Salguero J, Sánchez C, Sánchez-Vizcaíno JM, Torres JM (2003) Early detection of PrPres in BSE-infected bovine PrP transgenic mice. Arch Virol 148:677-691.

Collinge J, Rossor M (1996) A new variant of prion disease. Lancet 347:916-917.

Collinge J, Palmer MS, Sidle KC, Hill AF, Gowland I, Meads J, Asante E, Bradley R, Doey LJ, Lantos PL (1995) Unaltered susceptibility to BSE in transgenic mice expressing human prion protein. Nature 378:779-783.

Collinge J, Beck J, Campbell T, Estibeiro K, Will RG (1996) Prion protein gene analysis in new variant cases of Creutzfeldt-Jakob disease. Lancet 348:56.

Dickinson AG, Stamp JT, Renwick CC, Rennie JC (1968) Some factors controlling the incidence of scrapie in Cheviot sheep injected with a Cheviotpassaged scrapie agent. J Comp Pathol 78:313-321.

Fink PS (1991) Using sodium chloride step gradients to fractionate DNA fragments. Biotechniques 10:446,448,450.

Foster JD, Hope J, Fraser H (1993) Transmission of bovine spongiform encephalopathy to sheep and goats. Vet Rec 133:339-341.

Foster JD, Wilson M, Hunter N (1996) Immunolocalisation of the prion protein (PrP) in the brains of sheep with scrapie. Vet Rec 139:512-515.

Foster JD, Parnham D, Chong A, Goldmann W, Hunter N (2001) Clinical signs, histopathology and genetics of experimental transmission of BSE and natural scrapie to sheep and goats. Vet Rec 148:165-171.

Fraser H, Bruce ME, Chree A, McConnell I, Wells GA (1992) Transmission of bovine spongiform encephalopathy and scrapie to mice. J Gen Virol 73:1891-1897.

Hartsough GR, Burger D (1965) Encephalopathy of mink. Epizootiologic and clinical observations. J Infect Dis 115:387-392.

Hill AF, Joiner S, Linehan J, Desbruslais M, Lantos PL, Collinge J (2000) Species-barrier-independent prion replication in apparently resistant species. Proc Natl Acad Sci USA 97:10248-10253.

Hogan B, Williams J (1981) Integration of foreign genes into the mammalian germ line: genetic engineering enters a new era. Nature 294:9-10.

Kocisko DA, Priola SA, Raymond GJ, Chesebro B, Lansbury Jr PT, Caughey B (1995) Species specificity in the cell-free conversion of prion protein to protease-resistant forms: a model for the scrapie species barrier. Proc Natl Acad Sci USA 92:3923-3927.

Lasmezas CI, Deslys JP, Robain O, Jaegly A, Beringue V, Peyrin JM, Fournier
JG, Hauw JJ, Rossier J, Dormont D (1997) Transmission of the BSE agent to mice in the absence of detectable abnormal prion protein. Science 275:402-405.

Lopez Garcia F, Zahn R, Riek R, Wuthrich K (2000) NMR structure of the bovine prion protein. Proc Natl Acad Sci USA 97:8334-8339.

Manson JC, Clarke AR, Hooper ML, Aitchison L, McConnell I, Hope J (1994) 129/Ola mice carrying a null mutation in PrP that abolishes mRNA production are developmentally normal. Mol Neurobiol 8:121-127.

Pattison IH, Jones KM (1967) The possible nature of the transmissible agent of scrapie. Vet Rec 80:2-9.

Pattison IH, Jones KM (1968) Modification of a strain of mouse-adapted scrapie by passage through rats. Res Vet Sci 9:408-410.

Peretz D, Scott MR, Groth D, Williamson RA, Burton DR, Cohen FE, Prusiner SB (2001) Strain-specified relative conformational stability of the scrapie prion protein. Protein Sci 10:854-863.

Prusiner SB (1990) Novel structure and genetics of prions causing neurodegeneration in humans and animals. Biologicals 18:247-262.

Prusiner SB (1991) Molecular biology of prion diseases. Science 252: $1515-1522$.

Race R, Chesebro B (1998) Scrapie infectivity found in resistant species. Nature 392:770.

Riek R, Wider G, Billeter M, Hornemann S, Glockshuber R, Wuthrich K (1998) Prion protein NMR structure and familial human spongiform encephalopathies. Proc Natl Acad Sci USA 95:11667-11672.

Ryder SJ, Hawkins SA, Dawson M, Wells GA (2000) The neuropathology of experimental bovine spongiform encephalopathy in the pig. J Comp Pathol 122:131-143.

Scott M, Foster D, Mirenda C, Serban D, Coufal F, Walchli M, Torchia M, Groth D, Carlson G, DeArmond SJ (1989) Transgenic mice expressing hamster prion protein produce species-specific scrapie infectivity and amyloid plaques. Cell 59:847-857.

Scott MR, Groth D, Tatzelt J, Torchia M, Tremblay P, DeArmond SJ, Prusiner SB (1997a) Propagation of prion strains through specific conformers of the prion protein. J Virol 71:9032-9044.

Scott MR, Safar J, Telling G, Nguyen O, Groth D, Torchia M, Koehler R, Tremblay P, Walther D, Cohen FE, DeArmond SJ, Prusiner SB (1997b) Identification of a prion protein epitope modulating transmission of bovine spongiform encephalopathy prions to transgenic mice. Proc Natl Acad Sci USA 94:14279-14284.

Scott MR, Will R, Ironside J, Nguyen HO, Tremblay P, DeArmond SJ, Prusiner SB (1999) Compelling transgenetic evidence for transmission of bovine spongiform encephalopathy prions to humans. Proc Natl Acad Sci USA 96:15137-15142.

Telling GC, Scott M, Mastrianni J, Gabizon R, Torchia M, Cohen FE, DeArmond SJ, Prusiner SB (1995) Prion propagation in mice expressing human and chimeric PrP transgenes implicates the interaction of cellular PrP with another protein. Cell 83:79-90.

Vilotte JL, Soulier S, Essalmani R, Stinnakre MG, Vaiman D, Lepourry L, Da Silva JC, Besnard N, Dawson M, Buschmann A, Groschup M, Petit S, Madelaine MF, Rakatobe S, Le Dur A, Vilette D, Laude H (2001) Markedly increased susceptibility to natural sheep scrapie of transgenic mice expressing ovine PrP. J Virol 75:5977-5984.

Wells GA, Wilesmith JW (1995) The neuropathology and epidemiology of bovine spongiform encephalopathy. Brain Pathol 5:91-103.

Wells GA, Hawkins SA, Austin AR, Ryder SJ, Done SH, Green RB, Dexter I, Dawson M, Kimberlin RH (2003) Studies of the transmissibility of the agent of bovine spongiform encephalopathy to pigs. J Gen Virol 84:1021-1031. Westaway D, DeArmond SJ, Cayetano-Canlas J, Groth D, Foster D, Yang SL, Torchia M, Carlson GA, Prusiner SB (1994) Degeneration of skeletal muscle, peripheral nerves, and the central nervous system in transgenic mice overexpressing wild-type prion proteins. Cell 76:117-129.

Will R, Zeidler M (1996) Diagnosing Creutzfeldt-Jakob disease. BMJ 313:833-834.

Williams ES, Young S (1980) Chronic wasting disease of captive mule deer: a spongiform encephalopathy. J Wildl Dis 16:89-98.

Zahn R, Liu A, Luhrs T, Riek R, von Schroetter C, Lopez Garcia F, Billeter M, Calzolai L, Wider G, Wuthrich K (2000) NMR solution structure of the human prion protein. Proc Natl Acad Sci USA 97:145-150. 